\title{
Keanekaragaman Tumbuhan Paku di Kawasan Wisata Alam Candi Muncar Wonogiri Sebagai Bahan Penyusunan Modul Pembelajaran
}

\author{
Sulastri $^{1{ }^{*}}$, Tri Wiharti. ${ }^{2}$, Anwari Adi Nugroho. ${ }^{3}$ \\ ${ }^{123}$ Program Studi Pendidikan Biologi Universitas Veteran Bangun Nusantara Sukoharjo \\ *Alamat email koresponden: trilas898@gmail.com
}

\begin{abstract}
Abstrak
Kawasan Wisata Alam Pura Wonogiri Muncar memiliki beragam flora, termasuk pakis. Tujuan dari penelitian ini adalah untuk mengetahui keanekaragaman pakis dan hasil penelitian tersebut diharapkan dapat digunakan sebagai salah satu sumber pembelajaran biologi untuk SMA. Jenis penelitian ini adalah penelitian deskriptif dengan pendekatan kuantitatif. Metode yang digunakan adalah Purposive Sampling dengan sistem penempatan stasiun dan plot sesuai dengan lokasi lokasi penelitian. Berdasarkan hasil penelitian ditemukan 21 jenis pakis (Pteridophyta), di Kawasan Wisata Alam Candi Muncar, terdiri dari tiga kelas, yaitu kelas Filicinae, kelas Equisetinaceae dan kelas Lycopodiinae. Hasil validasi modul "Tumbuhan Paku (Pteridophyta)", diperoleh skor akhir dengan rata-rata 45,22 (skala 56) dengan nilai persentase $81 \%$, dapat disimpulkan bahwa modul pembelajaran biologi "Tumbuhan Paku (Pteridophyta) "dinyatakan memenuhi syarat sangat baik, digunakan sebagai modul pembelajaran biologi SMA.
\end{abstract}

Kata kunci: keanekaragaman pakis, modul pembelajaran biologi, kawasan wisata alam candi Muncar.

\section{Diversity of Nail Plants in Nature Tourism Areas Muncar Wonogiri Temple as Material for Preparing Learning Modules}

\author{
Sulastri $^{1}$ *, Tri Wiharti. ${ }^{2}$, Anwari Adi Nugroho. ${ }^{3}$ \\ ${ }^{123}$ Biology Education Departement, Universitas Veteran Bangun Nusantara Sukoharjo \\ *Correspondent's email address: trilas898@gmail.com
}

\begin{abstract}
Wonogiri Muncar Temple Natural Tourism Area has a variety of flora, including ferns. The purpose of this study is to find out the diversity of ferns and the results of the study are expected to be used as one of the sources of learning biology for high school. This type of research is descriptive research with a quantitative approach. The method used is Purpusive Sampling with the station placement system and plot according to the location of the research location. Based on the results of the study found 21 types of ferns (Pteridophyta), in the Muncar Temple Natural Tourism Area, consisting of three classes, namely the Filicinae class, Equisetinaceae class and Lycopodiinae class. The results of the module validation "Plant Paku (Pteridophyta)", obtained the final score with an average of 45.22 (scale 56) with a percentage value of $81 \%$, it can be concluded that the biology learning module "Plant Paku (Pteridophyta)" is declared eligible very good, used as a high school biology learning module.
\end{abstract}

Keywords: fern diversity, biology learning module, Muncar temple natural tourism area. 


\section{PENDAHULUAN}

Keanekaragaman adalah suatu cara pengukuran yang memadukan jumlah spesies (kelimpahan) dan penyebaran jumlah individu (distribusi). Oleh karena itu maka keanekaragaman merupakan ukuran integrasi yang memadukan antara kelimpahan spesies dengan penyebaran spesies tersebut (Nybakken, 1992). Pteridophyta hidup tersebar luas di daerah tropis yang lembab. Jumlah yang teramat besar dijumpai di hutan hujan tropis dan juga tumbuh subur didaerah iklim sedang, dihutan-hutan, dan sepanjang jalan aliran sungai. (Arini,2012 \& Tjitrosomo, 1983).

Kawasan Wisata Alam Candi Muncar, yaitu wisata air terjun dan telaga. Kawasan Wisata Alam Candi Muncar terletak di desa Bubakan, kecamatan Girimarto, kabupaten Wonogiri.

Berdasarkan hasil di Kawasan Wisata Alam Candi Muncar menunjukkan terdapat beranekaragam jenis tumbuhan paku. Tumbuhan paku merupakan suatu divisi yang warganya telah jelas mempunyai kormus, artinya tumbuhan yang dapat dibedakan dalam tiga bagian pokoknya, yaitu akar, batang, dan daun. Ciri khas dari tumbuhan paku adalah adanya daun muda yang menggulung dan akan membuka saat dewasa (Tjitrosoepomo, 1994). Tumbuhan paku diklsifikasikan dalam beberapa kelas termasuk yang sudah punah (Tjitroseopomo, 1994) : Kelas Psilophytinae; Kelas Lycopodinae; Kelas Equisetinae (Paku Ekor Kuda) Equisetum ; Kelas Filicinae (Paku Sejati) Filicinae memiliki akar, batang, dan daun sejati. (Tjitroseopomo, 1994).

Tumbuhan paku di kawasan Wisata

Alam Candi Muncar juga belum diidentifikasi keanekaragaman dan kemelimpahan jenisnya. Keragaman tumbuhan paku merujuk pada keanekaragaman spesies yang dihitung menggunakan indeks keragaman ShannonWiener (Nugroho, 2013). Kemelimpahan tumbuhan paku merujuk pada kemelimpahan spesies yang diinterprestasikan ke dalam Indeks Nilai Penting (Widhiastuti et al, 2006). Hasil identifikasi keanekaragaman tumbuhan paku di kawasan wisata alam Candi Muncar dapat di manfaatkan sebagai salah satu bahan ajar berupa modul untuk pembelajaran biologi SMA. Berdasarkan hasil wawancara dari beberapa sekolah di Kabupaten Wonogiri, yaitu SMA N 1 Girimarto dan SMA N 1 Sidoarjo, guru biologi SMA tersebut mengatakan bahwa pada saat proses pembelajaran, umumnya bahan ajar di SMA hanya berupa buku dan LKS (Lembar Kerja Siswa) yang diperoleh dari percetakan swasta. Akibatnya banyak kesulitan yang dialami oleh siswa saat pembelajaran dunia tumbuhan dan nilai ketuntasan siswa juga masih rendah. Nilai ketuntasan siswa pada ulangan harian dunia tumbuhan di S MA N 1 Girimarton untuk kelas MIPA 1, 53,125\% (17 tuntas dari 32 siswa) dan MIPA 2, hanya 22,22\% (8 tuntas dari 36 siswa). Untuk nilai ketuntasan di SMA N 1 Sidoarjo tidak jauh berbeda. Nilai ketuntasan siswa pada ulangan harian dunia tumbuhan adalah 22,22\% (6 tuntas dari 27 siswa). Modul Pteridophyta hasil identifikasi tumbuhan paku dikawasan Wisata Alam Candi Muncar dapat membuka kesempatan kepada siswa untuk maju berkelanjutan menurut kemampuannya masing-masing, membuka kesempatan kepada siswa untuk mengembangkan dirinya secara optimal (Nugroho \& Subiyantoro,2003).

\section{METODE}

Penelitian ini dilaksanakan di Kawasan Wisata Alam Candi Muncar dusun Siroto, desa Bubakan, kecamatan Girimarto, kabupaten Wonogiri. Selama 6 bulan yaitu pada bulan Desember 2017 sampai bulan Juni 2018. Alat dan bahan yang digunakan dalam penelitian. 
Tabel 1. Alat-alat penelitian

\begin{tabular}{|c|c|c|c|}
\hline No & Alat & Kuantitas & Keterangan \\
\hline 1 & $\begin{array}{l}\text { Bilah } \\
\text { bambu, }\end{array}$ & 4 & $\begin{array}{l}\text { Untuk membuat } \\
\text { plot }\end{array}$ \\
\hline 2 & Tali rafia & 1 gulung & Pembatas plot \\
\hline 3 & Alat tulis & 1 & $\begin{array}{l}\text { Mendaftar } \\
\text { tumbuhan paku } \\
\text { yang ditemukan }\end{array}$ \\
\hline 4 & $\begin{array}{l}\text { Pisau/guntin } \\
\mathrm{g}\end{array}$ & 2 & Memotong rafia \\
\hline 5 & Sasak kayu & 8 & $\begin{array}{l}\text { Membuat } \\
\text { herbarium }\end{array}$ \\
\hline 6 & Koran bekas & 4 lembar & $\begin{array}{l}\text { Membuat } \\
\text { herbarium }\end{array}$ \\
\hline 7 & $\begin{array}{l}\text { Kantong } \\
\text { plastik }\end{array}$ & 1 pak & $\begin{array}{l}\text { Wadah sampel } \\
\text { tumbuhan paku }\end{array}$ \\
\hline 8 & $\begin{array}{l}\text { Kertas ph } \\
\text { meter }\end{array}$ & 1 & $\begin{array}{l}\text { Mengukur ph } \\
\text { tanah }\end{array}$ \\
\hline 9 & Termometer & 1 & $\begin{array}{l}\text { Mengukur suhu } \\
\text { Mengukur }\end{array}$ \\
\hline 10 & Hydometer & 1 & $\begin{array}{l}\text { kelembapan } \\
\text { udara }\end{array}$ \\
\hline 11 & Stopwatch & 1 & $\begin{array}{l}\text { Mengukur } \\
\text { kecepatan angin }\end{array}$ \\
\hline 12 & $\begin{array}{l}\text { Tabung } \\
\text { reaksi }\end{array}$ & 1 & $\begin{array}{l}\text { Wadah sampel } \\
\text { tanah }\end{array}$ \\
\hline 13 & Aquades & 1 botol & $\begin{array}{l}\text { Komponen } \\
\text { mengukur ph } \\
\text { tanah }\end{array}$ \\
\hline 14 & Tisu & 3 lembar & $\begin{array}{l}\text { Mengukur } \\
\text { kecepatan angin }\end{array}$ \\
\hline 15 & $\begin{array}{l}\text { Kamera } \\
\text { dokumentasi }\end{array}$ & 1 & $\begin{array}{l}\text { Dokumentasi } \\
\text { penelitian }\end{array}$ \\
\hline
\end{tabular}

Jenis penelitian adalah penelitian deskriptif dengan pendekatan kuantitatif, dengan metode Purposive Sampling adalah teknik penentuan sampel dengan mempertimbangkan suatu hal tertentu. (Widhiastuti et al, 2006 ; Efendi, 2013) Pengamatan di bagi menjadi 3 stasiun berdasarkan ketinggian (Widhiastuti et al, 2006 ; Kurniawati dkk, 2016). Stasiun yang telah ditentukan (1000-1010 m dpl) stasiun 1, (985-1000) m dpl stasiun 2, (890-910 m dpl) stasiun 3. Setiap stasiun di buat dengan ukuran $100 \mathrm{~m} \times 100 \mathrm{~m}$, yang dibagi menjadi 3 plot dengan ukuran $10 \mathrm{~m}$ $\mathrm{x} 10 \mathrm{~m}$ ukuran kuadrat yang ditentukan untuk semak (semak berkayu) (Kent \& Coker dalam Heriyanto, 2008 ). Total plot dari tiga stasiun seluruhnya adalah 9 plot, Penentuan plot pengamatan tersebut dilakukan secara purposive (sengaja), dengan melihat komposisi jenis dan jumlah tumbuhan paku (pteridophyta).

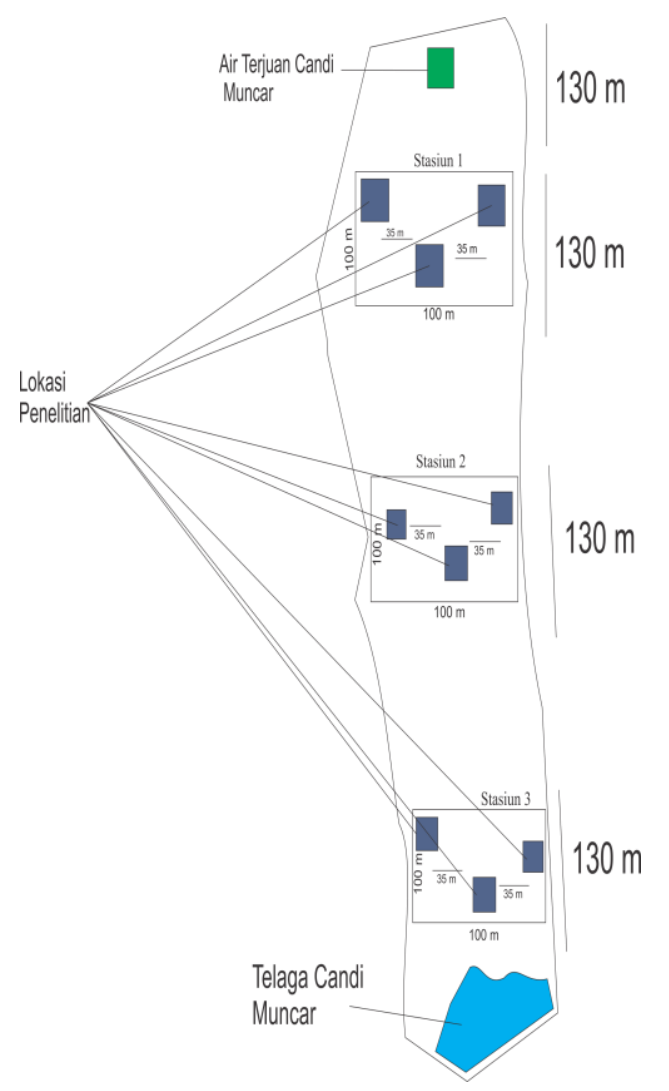

Gambar 1. Peta Lokasi Candi Muncar Dusun Siroto, Desa Bubakan, Kecamatan Girimarto, Kabupaten Wonogiri

Langkah-langkah

dalam pengumpulan data, yaitu: (a) menyiapkan alat dan bahan yang akan digunakan pada penelitian; (b) melakukan observasi dan membuat plot pada setiap stasiun yang telah ditentukan dengan menggunakan metode purposive sampling. Plot yang digunakan adalah bujur sangkar dengan ukuran $10 \mathrm{~m} \times 10 \mathrm{~m}$. Jarak minimal tiap plot adalah 35 meter. Pada penelitian ini di buat 3 plot pada setiap stasiun; (c) mengukur ketinggian, kelembaban, suhu, intensitas cahaya dan $\mathrm{pH}$ tanah; (d) mencari jenis tumbuhan paku (pteridophyta) pada plot yang telah dibuat; (e) jenis tumbuhan paku (pteridophyta) yang ditemukan difoto/video kemudian 
diambil sempelnya dan dibuat koleksi;(f)memberikan label pada setiap sampel tumbuhan paku (pteridophyta) yang ditemukan pada masing-masing plot;

Analisis data menggunakan Indeks

Nilai Penting dan Indek Keragaman Shannon-Wiener:

Menurut (Widhiastuti et al, 2006)

INP dihitung dengan rumus sebagai berikut:

Kerapatan mutlak jenis i (Kmi)

$\mathrm{KMi}=\frac{\text { jumlah } \text { individu suatu jenis }(i)}{\text { jumlah total luas penarikan contoh }}$

Kerapatan relatif jenis i (Kri)

$\mathrm{KRi}=\frac{\text { kerapatan mutlak } \text { jenis }(i)}{\text { kerapatan total seluruh jenis }} \times 100 \%$

Frekuensi mutlak jenis i (FMi)

$\mathrm{FMi}=\frac{\text { jumlah satuan petak diduduki jenis }(i)}{\text { jumlah petak contoh yang dibuat }}$

Frekuensi relatif jenis i (FRi)

$$
\mathrm{FRi}=\frac{\text { frekuensi mutlak jenis }(i)}{\text { jumlah frekuensi seluruh jenis }} \times 100 \%
$$

Indeks Nilai Penting (INP)

INP $=$ Kerapatan Relatif + Frekuensi Relatif

Indeks Keragaman

Indeks keragaman yang digunakan adalah indeks keragaman Shannon-Wiener (Nugroho, 2013):

$$
\mathrm{H}^{\prime}=-\sum_{i=1}^{S} p i \ln p i
$$

Keterangan:

$H^{\prime}$ : Indeks keragaman ShannonWiener

pi : ni/N

ni : Jumlah individu suatu jenis

$\mathrm{N}$ : Jumlah total individu

$S$ : Jumlah jenis
Kisaran nilai hasil perhitungan indeks keragaman (H') menunjukkan bahwa (Odum, 1998):

$\mathrm{H}^{\prime}>3,322 \quad$ : keragaman spesies tinggi, produktifitas tinggi;

$1,0<\mathrm{H}^{\prime}<3,322$ : keragaman spesies sedang, produktifitas sedang;

$\mathrm{H}^{\prime}<1,0 \quad$ : keragaman spesies rendah produktifitas rendah

Hasil penelitian tumbuhan paku (pteridophyta) di Kawasan Wisata Alam Candi Muncar, dibuat bahan ajar berbentuk modul. Tahap-tahap penyusunan bahan ajar berupa modul yaitu: 1) Judul yang digunakan untuk bahan ajar adalah modul Pteridophyta (tumbuhan paku); 2) Sumber buku yang akan digunakan untuk menyusun modul Pteridophyta (tumbuhan paku) : Flora, Taksonomi Tumbuhan,buku paket SMA dan jurnal; 3) Melakukan identifikasi terhadap kurikulum sampai Kompetensi Dasar, melakukan kajian terhadap materi pembelajarannya, serta merancang bentuk kegiatan pembelajaran yang sesuai. Kurikulum yang digunakan adalah kurikulum 2013 dengan kompetensi dasar 3.7: menerapkan prinsip klasifikasi untuk menggolongkan tumbuhan ke dalam divisio berdasarkan morfologi dan metagenesis tumbuhan serta mengkaitkan peranannya dalam keberlangsungan kehidupan di bumi; 4) Mengidentifikasi indikator pencapaian kompetensi. Materi pada modul pteridophyta di sesuaikan dengan materi Plantae pada SMA kelas X, berdasarkan hasil identifikasi Tumbuhan Paku di Kawasan Wisata Alam Candi Muncar yaitu: (a) Penyusunan modul pteridophyta dengan kompetensi dasar 3.7, disesuaikan dengan penilaian kognitif, afektif, dan psikomotor; (b) Validasi ahli materi dan pengguna; (c) Penilaian modul mengacu pada tabel kalayakan modul . 
Tabel 2. Kriteria kelayakan modul (Nugroho \& Subiyantoro, 2017)

\begin{tabular}{llll}
\hline \multicolumn{1}{c}{ Interval kriteria } & \multicolumn{1}{c}{ kriteria } & \multicolumn{1}{c}{ Kualifikasi } & \multicolumn{1}{c}{ Keterangan } \\
\hline $81 \% \leq \mathrm{N}<100 \%$ & Layak & Sangat Baik & Tidak perlu revisi \\
$62 \% \leq \mathrm{N}<81 \%$ & Cukup Layak & Baik & Tidak perlu revisi \\
$43 \% \leq \mathrm{N}<62 \%$ & Kurang Layak & Cukup & Revisi \\
$24 \% \leq \mathrm{N}<43 \%$ & Tidak Layak & Kurang & Revisi \\
\hline
\end{tabular}

\section{HASIL DAN PEMBAHASAN}

Identifikasi Tumbuhan Paku

Hasil identifikasi tumbuhan paku di Wisata Alam Candi Muncar desa Bubakan, Kecamatan Girimarto, Kabupaten Wonogiri, ditemukan 21 spesies tumbuhan paku, Identifikasi tersebut didasarkan pada taksonomi terbaru (Kinho, 2009; (Lubis, 2009) ; (Widhiastuti,et al, 2006) ; (Tjitrosoepomo, G. 2003); Armi (2017); (Ceri dkk,2014), terdiri dari 3 kelas yaitu kelas Lycopodinae, kelas Equisetinae, dan kelas Filicinae, dan 16 famili, antara lain sebagai berikut.

Famili Marattiaceae, spesies Angiopteris evecta; famili Cyatheaceae, spesies Cyathea contaminans; famili Davaliaceae, spesies Davalia solida dan Cheilanthes farinosa ; famili Polypodiaceae, spesies Drynaria rigidula,
Heterogonium sp dan Crypsinus enervis ; famili Dryopteridaceae spesies Bolbitis sp; famili Selaginelaceae, spesies Selaginela intermedia ; famili Thelyptheridaceae, spesies Sphaerostephanos polycarpus dan Christella parasitica ; famili Gleicheniaceae, spesies Gleichenia linearis ; famili Hymenophyllaceae, spesies Hymenoplepis spicata ; famili Adiantaceae, spesies Adiantum caudatum ; famili Equisetinaceae, spesies Equisetum debile ; famili Blechnaceae, spesies Blechnum patersoni dan Stenochlaena palustris ; famili Oleandaraceae, spesies Neprhrolepis biserrata; famili Aspleniaceae, spesies Asplenium pellucidum ; famili Dicksoniaceae, spesies Cibotium baranetz ; famili Athyriaceae, spesies Diplazum accendens

Tabel 3. Jenis Tumbuhan Paku di Kawasan Wisata Alam Candi Muncar

\begin{tabular}{|c|c|c|c|c|c|c|c|c|c|}
\hline No & Kelas & Famili & Nama Ilmiah & $\sum$ & $\begin{array}{c}\mathbf{K r} \\
(\%)\end{array}$ & $\begin{array}{l}\text { Fr } \\
(\%)\end{array}$ & INP & RANK & H' \\
\hline 1. & Lycopodiinae & Selaginelaceae & $\begin{array}{l}\text { Selaginela } \\
\text { intermedia }\end{array}$ & 178 & 13,51 & 8,62 & 0,221 & 1 & 0,345524 \\
\hline 2. & Filicinae & Thelyptheridaceae & $\begin{array}{l}\text { Sphaerostephan } \\
\text { os polycarpus }\end{array}$ & 323 & 11,05 & 8,62 & 0,197 & 2 & 0,255951 \\
\hline 3. & Filicinae & Gleicheniaceae & $\begin{array}{l}\text { Gleicheina } \\
\text { linearis }\end{array}$ & 246 & 11,15 & 5,17 & 0,163 & 3 & 0,257219 \\
\hline 4. & Filicinae & Oleandaraceae & $\begin{array}{l}\text { Neprolepis } \\
\text { biserrata }\end{array}$ & 122 & 12,86 & 1,72 & 0,146 & 4 & 0,143893 \\
\hline 5. & Filicinae & Cyatheaceae & $\begin{array}{l}\text { Cyathea } \\
\text { contaminans }\end{array}$ & 112 & 0,73 & 13,79 & 0,145 & 5 & 0,082382 \\
\hline 6. & Filicinae & Davaliaceae & Davalia solida & 68 & 1,55 & 12,07 & 0,136 & 6 & 0,115142 \\
\hline 7. & Filicinae & Davaliaceae & $\begin{array}{l}\text { Cheilanthes } \\
\text { farinosa }\end{array}$ & 634 & 8,07 & 5,17 & 0,132 & 7 & 0,214775 \\
\hline 8. & Filicinae & Blechnaceae & $\begin{array}{l}\text { Blechnum } \\
\text { patersoni }\end{array}$ & 463 & 7,35 & 5,17 & 0,125 & 8 & 0,203246 \\
\hline 9. & Filicinae & Hymenophyllaceae & $\begin{array}{l}\text { Hymenoplepis } \\
\text { spicata }\end{array}$ & 38 & 8,44 & 3,45 & 0,119 & 9 & 0,172096 \\
\hline
\end{tabular}




\begin{tabular}{|c|c|c|c|c|c|c|c|c|c|}
\hline No & Kelas & Famili & Nama Ilmiah & $\sum$ & $\begin{array}{l}\mathbf{K r} \\
(\%)\end{array}$ & $\begin{array}{c}\mathrm{Fr} \\
(\%)\end{array}$ & INP & RANK & $\mathbf{H}^{\prime}$ \\
\hline 10. & Filicinae & Polypodiaceae & $\begin{array}{l}\text { Drynaria } \\
\text { rigidula }\end{array}$ & 53 & 2,33 & 5,17 & 0,075 & 10 & 0,093964 \\
\hline 11. & Filicinae & Adiantaceae & $\begin{array}{l}\text { Adiantum } \\
\text { caudatum }\end{array}$ & 16 & 0,41 & 6,90 & 0,073 & 11 & 0,030425 \\
\hline 12. & Filicinae & Thelypteridaceae & $\begin{array}{l}\text { Christella } \\
\text { parasitica }\end{array}$ & 18 & 2,13 & 5,17 & 0,073 & 12 & 0,08774 \\
\hline 13. & Filicinae & Dryopteridaceae & Bolbitis sp & 91 & 4,76 & 1,72 & 0,065 & 13 & 0,070552 \\
\hline 14. & Filicinae & Marattiaceae & $\begin{array}{l}\text { Angiopteris } \\
\text { evecta }\end{array}$ & 31 & 2,87 & 3,45 & 0,063 & 14 & 0,08129 \\
\hline 15. & Equisetinae & Equisetinaceae & $\begin{array}{l}\text { Equisetum } \\
\text { debile }\end{array}$ & 1292 & 1,78 & 3,45 & 0,052 & 15 & 0,056513 \\
\hline 16 & Filicinae & Aspleniaceae & $\begin{array}{l}\text { Asplenium } \\
\text { pellucidum }\end{array}$ & 196 & 2,77 & 1,72 & 0,045 & 16 & 0,046575 \\
\hline 17. & Filicinae & Polypodiaceae & $\begin{array}{l}\text { Heterogonium } \\
s p\end{array}$ & 110 & 2,56 & 1,72 & 0,043 & 17 & 0,123172 \\
\hline 18. & Filicinae & Blechnaceae & $\begin{array}{l}\text { Stenochlaena } \\
\text { palustris }\end{array}$ & 640 & 1,99 & 1,72 & 0,037 & 18 & 0,035814 \\
\hline 19. & Filicinae & Dicksoniaceae & $\begin{array}{l}\text { Cibotium } \\
\text { baranetz. }\end{array}$ & 37 & 1,93 & 1,72 & 0,037 & 19 & 0,03506 \\
\hline 20. & Filicinae & Athyriaceae & $\begin{array}{l}\text { Diplazum } \\
\text { accendens }\end{array}$ & 422 & 0,94 & 1,72 & 0,027 & 20 & 0,019539 \\
\hline \multirow[t]{2}{*}{21.} & Filicinae & Polypodiaceae & Crysinus enervis & 134 & 0,84 & 1,72 & 0,026 & 21 & 0,017729 \\
\hline & & & & & 100 & 100 & 2,00 & & 2,488599 \\
\hline
\end{tabular}

\section{Indeks Kemelimpahan dan Keanekaragaman}

Berdasarkan hasil identifikasi, dapat di hitung dominasi keanekaragaman dan kemelimpahan tumbuhan paku yang ada di Kawasan Wisata Alam Candi Muncar. Cara mengetahui jenis tumbuhan paku yang dominan di kawasan wisata Alam Candi Muncar dapat diperoleh dari nilai INP (Indeks Nilai Penting). Sebagaimana menurut (Lubis, 2009) bahwa indeks nilai penting merupakan parameter kuantitatif untuk menyatakan dominansi (tingkat penguasaan) spesiesspesies di dalam suatu komunitas tumbuhan. Spesies-spesies yang dominan dalam suatu komunitas tumbuhan akan memiliki nilai INP yang tinggi. sehingga spesies yang paling dominan akan mempunyai nilai INP yang paling besar dibandingkan dengan yang lainnya.

Menurut (Lubis, 2009) nilai INP (Indeks Nilai Penting) menyatakan kepentingan suatu jenis tumbuhan serta memperlihatkan peranannya dalam komunitas. Sedangkan nilai INP tersebut diperoleh dari penjumlahan nilai KR dengan FR. Berdasarkan Tabel 4.3, tampak bahwa tumbuhan paku yang memiliki nilai INP terbesar adalah Equisetumm debile, sebesar 13,51\%, kemudian Cheilanthes farinosa. $11,05 \%$ dan Stenochlaena palustris sebesar $11,15 \%$. Ketiga tumbuhan paku tersebut adalah tumbuhan yang dominan di kawasan wisata Alam Candi Muncar, sedangkan Equisetumm debile merupakan tumbuhan yang paling dominan. Hal ini dikarenakan oleh beberapa faktor yaitu faktor lingkungan dan perkembangbiakan. Spora pada Equisetumm debile berbentuk kecil dan bergerombol sehingga mudah menyebar dan pergiliran keturunannya berlangsung cepat. Hal ini sesuai dengan teori Indrawan (1978) di dalam Lubis (2009) menjelaskan bahwa tumbuh-tumbuhan yang mempunyai adaptasi tinggilah yang bisa hidup bahkan mendominasi di suatu daerah. Selain itu dipengaruhi pula oleh pertumbuhan dari bibit atau kecambah dari suatu jenis. 
Sedangkan lima tumbuhan paku dengan nilai INP terendah juga merupakan paku yang menempati lima komposisi terendah. Hal tersebut dikarenakan nilai INP adalah berbanding lurus dengan nilai KR dan juga FR. Semakin tinggi nilai KR dan FR, maka akan menyebabkan nilai INP semakin tinggi pula, dan begitu juga sebaliknya. Hal ini sesuai dengan teori Menurut Mackinon et al. (2000) dalam Lubis (2009) umumnya semakin ekstrim kondisi lingkungan, baik karena iklim, tanah atau ketinggian tempat yang bertambah, maka akan semakin berkurang keragaman komposisi jenis vegetasi dan satu atau dua jenis akan semakin dominan.

Tumbuhan paku yang ditemukan di Kawasan Wisata Alam Candi Muncar ada 21 spesies, jumlah total spesies sebanyak 1292 individu. Semua jenis tumbuhan paku yang ditemukan di Kawasan Wisata Alam Candi Muncar termasuk paku terestrial dan epifit. Hal ini disebabkan adanya tegakan yang didominasi oleh pohon dan pohon semak. Pada perhitungan dengan menggunakan Indeks Keanekaragaman Shannon-Weinner diperoleh hasil 2,48. berdasarkan teori (Odum, 1998), indeks keragaman 2,48 termasuk dalam kisaran sedang. Berdasarkan indeks tersebut, maka Kawasan Wisata Alam Candi Muncar cukup mendukung untuk kehidupan tumbuhan paku. Jika indeks keanekaragaman berkategori sedang berarti kondisi lingkungan di Kawasan Wisata Alam Candi Muncar relatif stabil. Besar kecilnya Indeks Keanekaragaman ada kaitannya dengan kondisi lingkungan. Lingkungan sebagai habitat sangat berpengaruh terhadap makhluk hidup yang tinggal di dalamnya.

Parameter lingkungan yang diukur pada saat penelitian di Kawasan Wisata Alam Candi Muncar, yaitu, $\mathrm{pH}$ tanah, kelembaban udara, intensitas cahaya, dan ketinggian tempat. $\mathrm{pH}$ tanah pada lokasi ditemukannya tumbuhan paku berada pada kisaran 5-6, berarti tanah cenderung asam. Menurut Indrawan (1978) di dalam Lubis (2009), pengaruh $\mathrm{pH}$ terhadap penyerapan zat hara dan pertumbuhan meliputi pengaruh dari zat beracun dan kelembaban zat hara. Apabila $\mathrm{pH}$ tanah $<7$ adalah asam dan apabila $\mathrm{pH}$ tanah > 7 adalahbasa. Sebagian besar paku-pakuan yang hidup di hutan tumbuh subur pada tanah dengan $\mathrm{pH}$ asam antara 5,5 - 6,5, tetapi di daerah berbatu paku-pakuan membutuhkan $\mathrm{pH}$ yang lebih basa, yaitu 7-8. Kelembaban udara juga berpengaruh terhadap penyerapan unsur hara dan laju pertumbuhan. Umumnya paku-pakuan yang hidup pada hutan tropis basah memerlukan kelembaban udara kurang lebih $7 \%$, jika kelembaban udara tersebut terpenuhi, maka paku-pakuan dapat tumbuh subur. Ketinggian pada lokasi penelitian berkisar antara 900 mdpl, sampai 1010 mdpl. Semakin tinggi lokasi penelitian, jenis tumbuhan paku yang ditemukan semakin homogen dan tidak terlalu banyak.

\section{Penyusunan Modul}

Tahapan penyusunan modul yang pertama, yaitu menentukan judul, judul yang digunakan adalah "Tumbuhan Paku (Pteridophyta)". Mencari sumber referensi tumbuhan paku dan referensi lain tentang pembuatan modul dari buku Flora, Buku Taksonomi Tumbuhan, Buku Paket SMA dan jurnal. Selanjutnya melaukan identifikasi terhadap kurikulum yang berlaku. Kurikulum yang digunakan adalah kurikulum 2013 dengan kompetensi dasar 3.7: menerapkan prinsip klasifikasi untuk menggolongkan tumbuhan ke dalam divisio berdasarkan morfologi dan metagenesis tumbuhan serta mengkaitkan peranannya dalam keberlangsungan kehidupan di bumi.

Kegiatan pembelajaran berlangsung dengan metode Discovery Learning. Untuk mengetahui layak dan tidaknya modul tersebut, maka dilakukan uji validasi pada 18 responden yang terdiri dari validator ahli materi dan ahli media yaitu dari dosen 
FKIP Biologi dan validator yang berasal dari guru SMA di Girimarto dan Sidoarjo, dan 14 siswa kelas XI SMA Negeri 1 Girimarto.

Pada ahli materi didapatkan nilai validasi sebesar 47 (skala 56), kemudian di konvertasikan ke dalam persen dan diperoleh sebanyak $84 \%$, yang kedua pada ahli materi dan modul diperoleh nilai validasi sebanyak 48 (skala 56) dikonversikan ke dalam persen didapatlkan $86 \%$. Yang kedua responden oleh

Tabel 4.Hasil uji Penilaian Modul

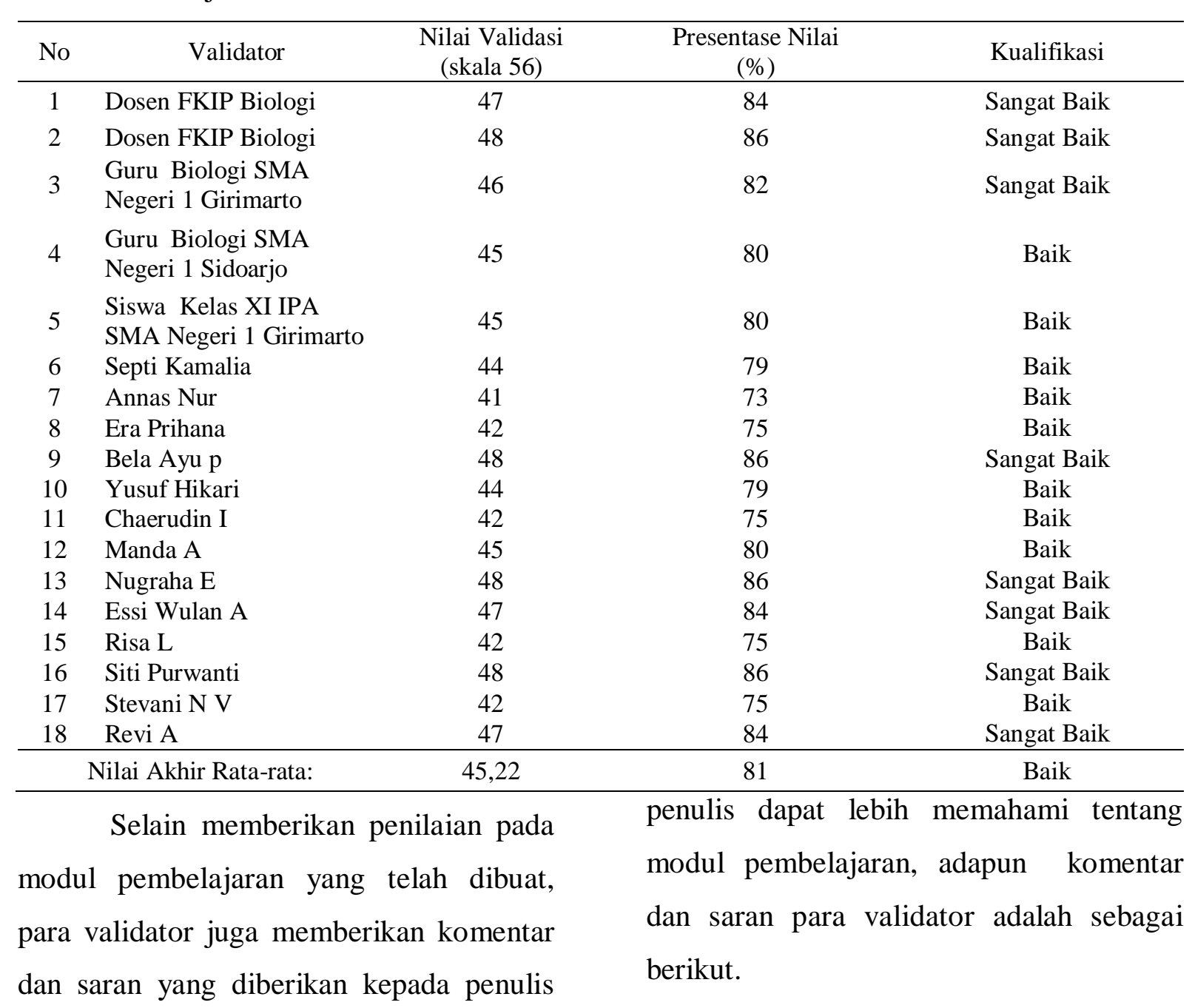

pengguna yaitu guru SMA N 1 Girimarto di dapatkan nilai validasi sebesar 48 (skala 56) dikonvertasikan ke dalam persen didapatkan $82 \%$, responden yang ke empat yaitu guru SMA N 1 Sidoharjo di dapatkan nilai validasi sebesar 45 (skala 56) di konvertasikan ke dalam persen diperoleh 80\%. Dari 14 responden siswa Sma di dapatkan rata-rata nilai validasi sebesar 44 dikonversikan ke dalam persen diperoleh sebanyak $79 \%$.

untuk perbaikan modul pembelajaran agar 
Tabel 5. Komentar dan saran Validator

\begin{tabular}{|c|c|c|}
\hline Validator & Komentar dan saran & Perbaikan \\
\hline $\begin{array}{l}\text { Responden ahli } \\
\text { materi Dosen FKIP }\end{array}$ & $\begin{array}{l}\text { 1. Keterangan gambar dilengkapi agar lebih } \\
\text { spesifik. }\end{array}$ & $\begin{array}{l}\text { 1. menambahkan keterangan } \\
\text { gambar }\end{array}$ \\
\hline Biologi & $\begin{array}{l}\text { 2. Keterangan gambar lebih diperbesar agar } \\
\text { mudah dibaca } \\
\text { 3. Dilengkapi dengan gambar sketsa dari } \\
\text { tumbuhan }\end{array}$ & $\begin{array}{l}\text { 2. memperbesar teks } \\
\text { 3. memberi gambar sketsa }\end{array}$ \\
\hline Responden ahli & 1. Belum ada daftar gambar & 1. memberi daftar gambar \\
\hline $\begin{array}{l}\text { media Dosen FKIP } \\
\text { Biologi }\end{array}$ & $\begin{array}{l}\text { 2. kutipan teks belum ditemukan yang ada } \\
\text { adalah sumber gambar pribadi } \\
\text { 3. gambar daur hidup supaya diperbesar agar } \\
\text { mudah dibaca }\end{array}$ & $\begin{array}{l}\text { 2. menambah kupian teks } \\
\text { 3. memperbesar teks daur } \\
\text { hidup }\end{array}$ \\
\hline Guru SMA Negeri 1 & 1. Rpp dilengkapi dengan lampiran penilaian & 1. melengkapi rpp, \\
\hline Girimarto & $\begin{array}{l}\text { 2. Daftar pustaka ditambahi } \\
\text { 3. Rangkuman materi diperjelas } \\
\text { 4. Penambahan kata di glosarium }\end{array}$ & $\begin{array}{l}\text { 2. daftar pustaka, } \\
\text { 3. melengkapi rangkuman } \\
\text { 4. menambahkan kata di } \\
\text { glosarium }\end{array}$ \\
\hline Annas Nur & Saya suka gambarnya & \\
\hline Era Prihana & Mudah dipahami & \\
\hline Bela Ayu p & Baik! & \\
\hline Yusuf Hikari & - & \\
\hline Chaerudin I & Modulnya mudah dipahami & \\
\hline Stevani N V & Ok! & \\
\hline Revi A & Menyenangkan saat dibaca & \\
\hline
\end{tabular}

Hasil rata-rata validasi nilai akhir dari 18 responden diperoleh nilai validasi sebesar 45,22 (skala 56) dengan presentase nilai $81 \%$ sehingga dapat disimpulkan bahwa modul pembelajaran biologi (Pteridophyta) yang telah di uji validasi dinyatakan layak dengan kualifikasi sangat baik untuk digunakan sebagai modul pembelajaran biologi Sma kelas $\mathrm{X}$ semester genap pada mata pelajaran Plantae. dengan keputusan produk baru siap dimanfaatkan dengan dilakukan revisi tidak terlalu besar dan tidak mendasar.

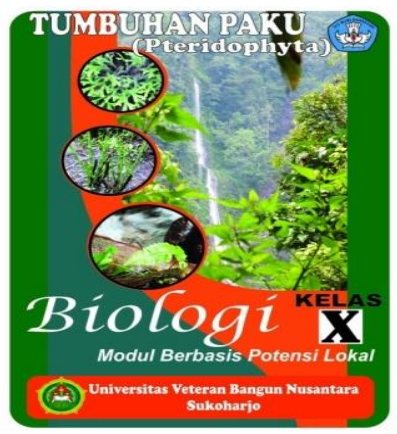

Gambar 2 Cover Modul Tumbuhan Paku (Pteridophyta)

Sumber : Dokumentasi Pribadi
Hal ini sesuai dengan teori (Nugroho \& Subiyantoro,2017) yang menyatakan bahwa Modul dengan metode Discovery Learning dapat mengembangkan kemampuan berpikir kritis mahasiswa pendidikan biologi. (Nugroho,2017) juga menyatakan bahwa pengembangan modul berbasis guided discovery untuk mengembangkan kemampuan berpikir kritis dan kemampuan sosial pada siswa. (Handoko dkk, 2016) juga menyatakan bahwa modul biologi hasil pengembangan memiliki karakteristik dilengkapi basis model Discovery Learning yang menekankan pada kerjasama kelompok layak digunakan dan dapat memberdayakan aspek sosial, aspek keterampilan dan aspek pengetahuan.

Sintak pembelajaran guided discovery yang diintegrasikan dalam komponen kegiatan belajar pada modul meliputi stimulation, problem statement, data collection, data processing, verification, dan generalization (Nugroho,2018). Penerapan Discovery Learning berbasis dapat meningkatkan 
keaktifan siswa dalam pembelajaran

\section{KESIMPULAN DAN SARAN}

\section{Kesimpulan}

Berdasarkan penelitian yang telah dilakukan mengenai Keanekaragaman Jenis Tumbuhan Paku (Pteridophyta) di Kawasan Wisata Alam Candi Muncar Girimarto, Wonogiri dapat diperoleh kesimpulan yaitu: 1) Jenis tumbuhan paku (Pteridophyta) yang ditemukan di Kawasan Wisata Alam Candi Muncar berjumlah 21 jenis yang terdiri dari tiga kelas, yaitu kelas Filicinae, kelas Equisetinaceae dan Kelas Lycopodiinae. Jenis paku dari Kelas Lycopodiinae yang ditemukan yaitu Selaginella intermedia, kelas Equisetinaceae yaitu Equisetum debile, kelas Filicinae ditemukan 19 jenis, yaitu Gleichneia lineralis, Davallia solida, Asplenium pellucidum, Nephrolepis biserrata, sphaerostephanos polycarpus, cyathea contaminans, cheilanthes farinose, Blechnum patersonii, Hymenoplepis spicata, Drynaria rigidula, Adiantum caudatum, Christella parasitica, Bolbitis $s p$, Angiopteris evecta, Heterogonium sp, Stenochlaena palustris, Cibotium baranetz, Diplazum accendens, Crypsinus enervis; 2) Hasil validasi modul "Tumbuhan Paku (Pteridophyta)" yang divalidasi oleh dosen ahli dan guru SMA di peroleh nilai akhir rata-rata yaitu, 45,22 (skala 56) dengan presentase nilai $81 \%$ sehingga dapat disimpulkan bahwa modul pembelajaran biologi "Tumbuhan Paku (Pteridophyta)" yang telah di uji validasi dinyatakan layak dengan dikualifikasikan sangat baik untuk digunakan sebagai modul pembelajaran biologi SMA kelas $\mathrm{X}$ semester Genap pada pelajaran Plantae.

\section{Saran}

Saran yang dituliskan dalam penelitian ini yaitu: 1) Bagi siswa, modul pembelajaran ini dapat digunakan sebagai sumber belajar dalam pembelajaran biologi, khususnya pada pembelajaran Plantae dan modul pembelajaran ini juga dapat membuat siswa belajar secara
(Supriyanto 2014).

langsung potensi lokal yang ada di daerah, sehingga pembelajaran dapat lebih bermakna; 2) Bagi guru, diharapkan modul pembelajaran ini dapat digunakan sebagai sumber informasi baru dan modul pembelajaran ini dapat digunakan sebagai referensi saat pembelajaran Plantae, khususnya Pteridophyta maka diharapkan dengan adanya modul Tumbuhan Paku (Pteridophyta)", guru dapat mengadakan pembelajaran dengan pengamatan secara langsung dengan memanfaatkan potensi lokal daerah; 3) Bagi Kawasan Wisata Alam Candi Muncar,diharapkan supaya mengadakan konservasi atau pembudidayaan tumbuhan paku mengingat manfaatnya sangat banyak, dan kedepannya selain sebagai wisata, juga dapat dijadikan sebagai tempat edukasi; 4) Bagi peneliti lain, perlu dilakukan penelitian lebih lanjut di Kawasan Wisata Alam Candi Muncar tentang tumbuhan lain yang belum pernah dilakukan identifikasi dan inventarisasi.

\section{UCAPAN TERIMAKASIH}

Ucapan terimakasih penulis sampaikan kepada lembaga Universitas Veteran Bangun Nusantara Sukoharjo, Dosen Pembimbing, dan pengelola Kawasan Wisata Alam Candi Muncar serta pihak-pihak terkait yang tidak dapat penulis sampaikan satu demi satu atas terselenggaranya penelitian tumbuhan paku (pteridophyta).

\section{DAFTAR PUSTAKA}

Arini, D, I, D., \& Kinho J. (2012). Keragaman Jenis Tumbuhan Paku (Pteridophyta) Di Cagar Alam Gunung Ambang Sulawesi Utara (The Pteridhopyta Diversity In Gunung Ambang Nature Reserve North Sulawesi).Jurnal BPK Manado, 2 (1).

Armi, J, M. (2017). Identifikasi Tumbuhan Paku (Pteridophyta) Sebagai Bahan Ajar Botani Tumbuhan Rendah Di Kawasan Tahura Pocut Meurah Intan Kabupaten Aceh Besar. Jurnal Pendidikan Sains : 5 (1), 
Campbell, N. A. \& Reece, J. B. (2012). Biologi. Jakarta: Erlangga.

Ceri, B. Lovadi, I. Linda, R.. (2014). Keanekaragaman Jenis Paku-Pakuan (Pteridophyta) Di Mangrove Muara Sungai Peniti Kecamatan Segedong Kabupaten Pontianak. Jurnal Protobiont, 3 (2) : $240-$ 246.

Depdiknas. (2008). Penulisan Modul. Departemen pendidikan Nasional Direktorat Jenderal Peningkatan Mutu Pendidik dan Tenaga Kependidikan Direktorat Tenaga Kependidikan.

Efendi, W,W., Hapsari, F,N,P.,\& Nuraini, Z. (2013). Studi Inventarisasi Keanekaragaman Tumbuhan Paku Di Kawasan Wisata Coban Rondo Kabupaten Malang. Cogito Ergo Sum, 2 (3).

Handoko,A, Sajidan, Maridi. (2016). Pengembangan Modul Biologi Berbasis Discovery Learning (Part Of Inquiry Spectrum Learning-Wenning) Pada Materi Bioteknologi Kelas Xii Ipa Di Sma Negeri 1 Magelang Tahun Ajaran 2014/2015. JURNAL INKUIRI ISSN: 2252-7893, 5.(3), 2016 (hal 144-154)

Hariyanto,S. (2008), Teori dan Praktik Ekologi, Surabaya,Airlangg University Press.

Lubis S. R. (2009). Keanekaragaman dan Pola Distribusi Tumbuhan Paku di Hutan Wisata Alam Taman Eden Kabupaten Toba Samosir Provinsi Sumatera Utara. Tesis, Medan, Universitas Sumatera Utara.

Nugroho, A. A., \& Subiyantoro, S. (2017). Pengembangan Modul Sistematika Tumbuhan Tinggi Berbasis Guided Discovery untuk Mengembangkan Kemampuan Berpikir Kritis Mahasiswa Pendidikan Biologi. BIOPEDAGOGI, 6(2), 19-24.
Nugroho, S, M., Ningsih, S., \& Ihsan, M. (2013). Keanekaragaman Jenis Burung Pada Areal Dongi-Dongi Di Kawasan Taman Nasional Lore Lindu. Jurnal Warta Rimba, 1 (1).

Nurchayati, N. (2010). Hubugan Kekekrabatan Beberapa Spesies Tumbuhan Paku Familia Polypodiaceae Ditinjau Dari Karakter Morfologi Sporofit dan Gametofit. Jurnal Ilmiah .PROGRESIF, 7 (19).

Nybakken, J. W. (1992). Biologi Laut: Suatu Pendekatan Ekologis. Cetakan ke 2. Terjemahan H.M. Eidman, Koesoebiono, D.G. Bengen M. Hutomo \& S. Sukoharjo. Jakarta: PT Gramedia Pustaka Utama.

Odum, P. E. (1998), Dasar-dasar Ekologi, Yogyakarta, Gadjah Mada University Press.

Sastrapradja, J., Afriastini, D., \& Elizabeth. (1980). Jenis Paku Indonesia. Bogor, Lembaga Biologi Nasional.

Sayekti, F,H., Wibowo, Y.,Ratnawati. (2017). Pengembangan Modul Pengayaan Keanekaragaman Paku Wanagama Untuk Meningkatkan Kemandirian Belajar Siswa Sma Di Gunungkidul. Jurnal Prodi Pendidikan Biologi, 6 (6).

Sugiyono. (2010). Metode Penelitian Kuantitatif Kualitatif dan $R \& D$, Bandung : Alfabeta.

Tjitrosoepomo, G. (2003). Taksonomi Tumbuhan, Gajah Mada University Press, Yogyakarta.

Widhiastuti, R., T. A. Aththorick \& W. D. P. Sari, (2006). Struktur dan Komposisi Tumbuhan Paku-pakuan di Kawasan Hutan Gunung Sinabung Kabupaten Karo. Jurnal Biologi Sumatera, 1 (2) Juli 2006.

Wijaya, C. (1992). Upaya Pembaharuan dalam Pendidikan dan Pengajaran. Jakarta: Bina Aksara 